\title{
Are emergency medical services offload delay patients at increased risk of adverse outcomes?
}

\author{
Dana Stewart, MD, BSc * Eddy Lang, MD*; Dongmei Wang, MSc*; Grant Innes, MD*
}

\section{CLINICIAN'S CAPSULE}

What is known about the topic? Emergency medical services (EMS) offload delay leads to patient discomfort, negatively affects care, and prevents EMS crews from providing service in the community.

What did this study ask? Is EMS offload delay associated with an increased risk of adverse patient outcomes?

What did this study find? Offload delay was not associated with prolonged hospital length of stay or increased mortality.

Why does this study matter to clinicians? Recognizing the effects of EMS offload delay may facilitate the development of strategies to better address the issue of emergency department overcrowding.

\section{ABSTRACT}

Objective: Emergency department (ED) and hospital overcrowding cause offload delays that remove emergency medical services (EMS) crews from service and compromise care delivery. Prolonged ED boarding and delays to inpatient care are associated with increased hospital length of stay (LOS) and patient mortality, but the effects of EMS offload delays have not been well studied.

Methods: We used administrative data to study all high-acuity Canadian Triage Acuity Scale 2-3 EMS arrivals to Calgary adult EDs from July 2013 to June 2016. Patients offloaded to a care space within 15 minutes were considered controls, whereas those delayed $\geq 60$ minutes were considered "delayed." Propensity matching was used to create comparable control and delayed cohorts. The primary outcome was 7-day mortality. Secondary outcomes included hospital LOS and 30-day mortality.

Results: Of 162,002 high-acuity arrivals, 70,711 had offload delays $\leq 15$ minutes and 41,032 had delays $>60$ minutes. Delayed patients were more likely to be female, older, to have lower triage acuity, to live in dependent living situations, and to arrive on weekdays and day or evening hours. Delayed patients less often required admission and, when admitted, were more likely to go to the hospitalist service. Main outcomes were similar for propensity-matched control and delayed cohorts, although delayed patients experienced longer ED LOS and slightly lower 7-day mortality rates.

Conclusion: In this setting, high-acuity EMS arrivals exposed to offload delays did not have prolonged hospital LOS or higher mortality than comparable patients who received timely access.

\section{RÉSUMÉ}

Contexte: L'engorgement des hôpitaux et des services des urgences (SU) entraîne des retards de déchargement des ambulances et une suspension des services médicaux d'urgence (SMU), en plus de porter atteinte à la prestation de soins. Les séjours prolongés au SU et les retards de prestation de soins aux patients hospitalisés sont associés à une prolongation de la durée de séjour (DS) à I'hôpital et à une augmentation de la mortalité, mais on ne connaît pas très bien les effets des retards de déchargement des ambulances pour cause d'engorgement.

Méthode: Pour ce faire, nous avons utilisé des données administratives pour examiner tous les cas très urgents dont le degré de gravité était de 2 ou 3 sur l'Échelle canadienne de triage et de gravité et qui ont été traités dans l'un des SU pour adultes de Calgary, de juillet 2013 à juin 2016. Les patients qui ont été conduits dans un lieu de prestation de soins en moins de 15 minutes étaient considérés comme des témoins, tandis que ceux qui ont attendu $\geq 60$ minutes étaient considérés comme des "sujets en attente». Nous avons eu recours à l'appariement par score de propension pour former des cohortes comparables de témoins et de " sujets en attente ". Le principal critère d'évaluation était la mortalité au bout de 7 jours, et les critères d'évaluation secondaires comprenaient la DS à I'hôpital et la mortalité au bout de 30 jours.

Résultats: Sur 162002 cas très urgents, 70711 ont connu une attente $\leq 15$ minutes et 41032 , une attente $>60$ minutes. Les

From the *Department of Emergency Medicine, University of Calgary, Calgary, AB.

Correspondence to: Dr. Grant Innes, University of Calgary, Department of Emergency Medicine, 41612 Street NW, Calgary, AB T2N 1Y8; Email: grant.innes@albertahealthservices.ca 
personnes mises en attente étaient plus susceptibles d'être des femmes âgées, d'avoir un degré de gravité peu élevé au moment du triage, de vivre en état de dépendance et d'arriver les jours de semaine, de jour ou de soir. Les patients en attente avaient besoin moins souvent d'être hospitalisés et, le cas échéant, ils étaient plus susceptibles d'être mutés à l'étage. Les résultats du principal critère d'évaluation étaient comparables dans les deux cohortes; toutefois, les patients en attente ont connu une DS prolongée au SU, mais un taux de mortalité au bout de 7 jours légèrement inférieur à celui enregistré chez les autres patients.

Conclusion: Dans le contexte étudié, les patients arrivés en grande urgence par ambulance et mis en attente n'ont pas connu de séjour plus long à l'hôpital ou un taux de mortalité plus élevé que les patients comparables, traités en temps opportun.

Keywords: Hospital overcrowding, offload delay, patient mortality

\section{INTRODUCTION}

Ambulance offload delay is defined as a prolonged time between ambulance arrival and patient placement in an emergency department (ED) care space. ${ }^{1-4}$ Temporal thresholds for "delay" vary between studies; however, delays greater than 30 minutes are generally considered important. ${ }^{2,4,5}$ Hospital and ED overcrowding are the primary cause of ambulance offload delay, which occurs when the ED reaches maximum capacity and there are no available stretchers to accept newly arriving patients. ${ }^{1,6}$ Consequently, ambulance patients typically wait in hallways outside of the ED until a care space becomes available. This causes patient dissatisfaction and discomfort, negatively affects care quality, removes emergency medical services (EMS) crews from service, and compromises prehospital care delivery. ${ }^{1,3,7}$ The process of leaving acutely ill patients in hallways under the supervision of EMS crews also poses important ethical and legal questions regarding who is responsible to care for patients who have been registered in the hospital. The answer to this question seems obvious, yet many ED hallway patients continue to be monitored by paramedics, whose accountability and scope of practice are in the prehospital environment. $^{4}$

Many suggest that offload delays lead to inadequate pain management, delays to definitive care, and adverse outcomes, but patient level outcomes have not been well studied. ${ }^{3,4}$ Our objective is to address this knowledge gap and determine whether ambulance offload delay is associated with adverse system and patient outcomes. We hypothesize that EMS offload delay will be associated with both increased patient mortality and prolonged hospital length of stay (LOS).

\section{METHODS}

\section{Setting}

This propensity-matched observational cohort study was performed in the Calgary Health Zone, an integrated care delivery system with common regional leadership, program structures, operational processes, quality management, and information systems, serving 1.2 million people. We analysed administrative data describing EMS arrivals to Calgary's four adult EDs between July 2013 and June 2016. The study was subjected to the ARECCI Ethics Screening Tool and deemed to be a minimal risk quality improvement project, thus a formal ethics review was not required. ${ }^{8}$ (http://www.aihealthsolutions.ca/arecci/screening/328799/ 3ee489d6751747fbdde06364629e00b3)

\section{Patients}

The Canadian Triage Acuity Scale (CTAS) is a validated national triage tool used in all urban Canadian EDs that stratifies patients into five acuity levels (resuscitation to non-urgent). ${ }^{9}$ We studied all high-acuity CTAS 2 and 3 (emergent and urgent) patients who arrived by ambulance to a Calgary adult ED. Those assigned a care space within 15 minutes of triage were considered controls, whereas those delayed 60 minutes or longer from triage into a definitive ED care space were considered delayed. We chose > 60 minutes to define our "exposed" cohort because we felt (and previous authors have demonstrated) that 30-minute delays are too brief to cause outcome differences. ${ }^{10}$ We excluded "grey-zone" patients with 15- to 60-minute offload times because many urban Canadian EDs would consider these delays 


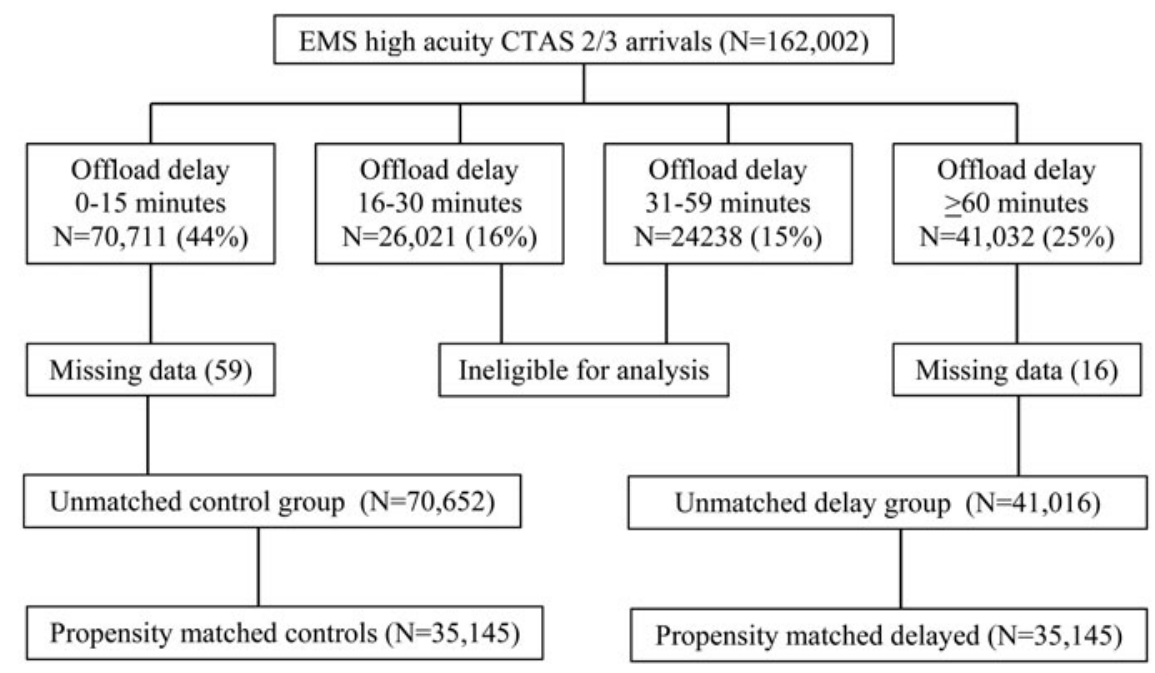

Figure 1. Study Flow Diagram.

acceptable, and because including these patients in either study cohort would blur the distinction between exposed and unexposed patients, potentially obscuring a harm signal if one exists.

\section{Data capture}

Patient demographics, living situation, arrival mode, complaint category, triage acuity, and index disposition were captured from the regional ED database. Inpatient diagnosis and hospital LOS were obtained from the hospital discharge abstract database, and mortality was determined through existing linkages with the provincial Vital Statistics registry. The linked administrative databases include reliable electronic time stamps for triage, time to care space, physician assessment, disposition decision, and inpatient transfer. "Time to care space" is the electronically captured time stamp when the nurse assigns a ready clean stretcher to a patient. This time does not include the subsequent interval required for the EMS crew to move the patient into the stretcher and provide handover to the bedside registered nurse; however, these process delays apply equally to both study cohorts. In Alberta, the provincial health system Data Integration Management and Reporting unit oversees all health system data capture, data management, and data quality.

\section{Outcomes}

Our primary outcome was 7-day mortality. Secondary outcomes included hospital LOS, 30-day mortality, left without being seen, and left against advice rates.

\section{Analysis}

Because patients were not randomly assigned to the delayed and control groups, we used propensitymatching techniques to reduce baseline covariate imbalance. R-statistical software, version 3.13 (The $\mathrm{R}$ Foundation for Statistical Computing; http://www.Rproject.org/), and the Matchit package were used to calculate propensity scores for each patient. ${ }^{11}$ For purposes of propensity matching, offload delay (60 minutes) was considered the dependent variable for logistic regression modelling. Multiple potential determinant variables, including age, sex, CTAS level, ED site, arrival day and time, number of ED visits within the preceding year, living situation (home care or care facility v. independent), presenting complaint category, and admitting service were regressed on the binary outcome of 60 -minute EMS offload delay. This logistic regression modelling provided, for each patient, a predicted probability of offload delay, which constituted that patient's propensity score. Nearest neighbour matching without replacement was used to create a control cohort with similar propensity score distribution to the delayed cohort (Figure 1). Unmatched patients were excluded from the analysis, as were patients with missing data. Matched cohorts were then compared on our outcomes of interest using risk difference and a 95\% confidence interval (CI), thus allowing for an "apples-to-apples" comparison of the delayed and control cohorts (Table 1). We agreed that propensity matching was preferable to multivariable adjustment because it allowed us to mimic a randomized trial structure and eliminate irrelevant observations 


\begin{tabular}{|c|c|c|c|c|}
\hline Outcome & Control & Delay & Difference & $95 \% \mathrm{Cl}$ \\
\hline n (\%) & 35,145 & 35,145 & & \\
\hline Left against advice & $236(0.7)$ & $261(0.7)$ & $0.0 \%$ & $-0.06,0.2$ \\
\hline Left without being seen & $238(0.7)$ & $230(0.7)$ & $0.0 \%$ & $-0.1,0.1$ \\
\hline ED LOS (all) in hours* & $8.2(7.3)$ & $10.6(8.8)$ & 2.4 & $2.3,2.5$ \\
\hline Hospital LOS (days)* & $4.4(12.3)$ & $4.2(12.4)$ & 0.2 & $-0.02,0.34$ \\
\hline Death within 7 days & $866(2.5)$ & $727(2.1)$ & $0.4 \%$ & $0.2,0.6$ \\
\hline Death within 30 days & $1,278(3.6)$ & $1,185(3.4)$ & $0.2 \%$ & $0,0.5$ \\
\hline
\end{tabular}

\begin{tabular}{|c|c|c|c|c|}
\hline & Control & Delay & Difference & $95 \% \mathrm{Cl}$ \\
\hline n (\%) & 70,652 & 41,016 & & \\
\hline Median offload delay: IQR & $8 \min (6,11)$ & $109 \min (80,162)$ & 101 & 100,102 \\
\hline Male sex & $36,437(51.6)$ & $18,660(45.5)$ & $6.1 \%$ & $5.5,6.7$ \\
\hline Mean age $(S D)^{*}$ & $58(22.5)$ & $61.5(21.97)$ & 3.5 & $3.2,3.7$ \\
\hline CTAS 2 & $42,145(59.7)$ & $16,289(39.7)$ & $20 \%$ & $19.3,20.5$ \\
\hline CTAS 3 & $28,507(40.3)$ & $24,727(60.3)$ & $20 \%$ & $19.3,20.5$ \\
\hline Fast offload site & $44,818(63.4)$ & $26,982(65.8)$ & $2.4 \%$ & $1.8,2.9$ \\
\hline Dependent living $\wedge$ & $9,516(13.5)$ & $7,225(17.6)$ & $4.1 \%$ & $3.7,4.6$ \\
\hline \multicolumn{5}{|l|}{ Arrival time } \\
\hline Day & $19,714(27.9)$ & $15,017(36.6)$ & $8.7 \%$ & $8.1,9.3$ \\
\hline Evening & $18,766(26.6)$ & $15,110(36.8)$ & $10.2 \%$ & $9.7,10.8$ \\
\hline Night & $32,172(45.5)$ & $10,889(26.5)$ & $19.0 \%$ & $18.4,19.6$ \\
\hline Weekday arrival & $43,914(62.2)$ & $32,314(78.8)$ & $16.6 \%$ & $16.1,17.2$ \\
\hline ED visits in prior year* & $1.08(1.21)$ & $1.19(1.23)$ & 0.11 & $10.0,13.0$ \\
\hline \multicolumn{5}{|l|}{ Complaint category } \\
\hline Medical & 12,609 (17.8) & $8,239(20.1)$ & $2.3 \%$ & $1.8,2.7$ \\
\hline Gastrointestinal & $10,752(15.2)$ & $9,862(24.0)$ & $8.8 \%$ & $8.3,9.3$ \\
\hline Cardiovascular & 13,669 (19.3) & $6,687(16.3)$ & $3.0 \%$ & $2.6,3.5$ \\
\hline Neurologic-mental health & $14,308(20.3)$ & $8,315(20.3)$ & $0.0 \%$ & $-0.5,0.5$ \\
\hline Trauma-related & $16,305(23.1)$ & $6,031(14.7)$ & $8.4 \%$ & $7.9,8.8$ \\
\hline Other & $3,009(4.3)$ & $1,882(4.6)$ & $0.3 \%$ & $0.1,0.6$ \\
\hline \multicolumn{5}{|l|}{ Admitting service } \\
\hline Hospitalist & $9,248(13.1)$ & $7,181(17.5)$ & $4.4 \%$ & $4.0,4.9$ \\
\hline Medicine & 7,491 (10.6) & $3,624(8.8)$ & $1.8 \%$ & $1.4,2.1$ \\
\hline Surgery & $6,580(9.3)$ & $3,025(7.4)$ & $1.9 \%$ & $1.6,2.2$ \\
\hline Cardiac & 2,519 (3.6) & 769 (1.9) & $1.7 \%$ & $1.5,1.9$ \\
\hline $\mathrm{ICU}$ & $997(1.4)$ & $245(0.6)$ & $0.8 \%$ & $0.7,0.9$ \\
\hline Psychiatry & 929 (1.3) & $425(1.0)$ & $0.3 \%$ & $0.15,0.4$ \\
\hline Other & $3,357(4.8)$ & 1,427 (3.5) & $1.3 \%$ & $1.0,1.5$ \\
\hline
\end{tabular}




\begin{tabular}{|c|c|c|}
\hline Factor & Adjusted OR & $95 \% \mathrm{Cl}$ \\
\hline Slow offload site & 1.6 & $1.5-1.7$ \\
\hline Weekday arrival & 1.38 & $1.35-1.41$ \\
\hline Low acuity (CTAS 3) & 1.27 & $1.24-1.29$ \\
\hline Evening arrival & 1.18 & $1.15-1.21$ \\
\hline Dependent living & 1.15 & $1.1-1.2$ \\
\hline Prior ED visits & $1.06^{*}$ & $1.05-1.07$ \\
\hline Female sex & 1.06 & $1.04-1.08$ \\
\hline Age & $1.01^{\wedge}$ & $1.007-1.01$ \\
\hline Night arrival & 0.71 & $0.69-0.73$ \\
\hline \multicolumn{3}{|l|}{ Complaint category } \\
\hline Medical & 1.0 & Reference \\
\hline Cardiovascular & 0.9 & $0.87-0.93$ \\
\hline Neurologic-mental health & 0.9 & $0.87-0.93$ \\
\hline Gastrointestinal & 0.85 & $0.82-0.87$ \\
\hline Trauma/musculoskeletal & 0.61 & $0.59-0.63$ \\
\hline Other & 0.77 & $0.73-0.81$ \\
\hline \multicolumn{3}{|c|}{$\begin{array}{l}\mathrm{Cl}=\text { confidence interval; OR = odds ratio. Dependent living refers to institutional } \\
\text { residence or home care involvement. Weekday arrival is in contrast to weekend or holiday } \\
\text { arrival. Day is 0800-1600 hours. Evening is } 1600-2400 \text { hours. Night is } 2400-0800 \text { hours. } \\
\text { *Odds ratio is } 1.06 \text { per ED visit during the prior year. } \\
\text { ^Odds ratio is } 1.01 \text { per year of age. }\end{array}$} \\
\hline
\end{tabular}

(incomparable patients) before performing any analyses, even though this technique leads to loss of sample size.

\section{RESULTS}

Figure 1 shows that 162,002 high-acuity EMS patients arrived during our study period; of these, $56 \%, 40 \%$, and $25 \%$ experienced offload delays greater than 15 , 30 , and 60 minutes, respectively. Table 2 shows that median (interquartile range [IQR]) offload time was 8 $(6-11)$ minutes in the control group and 109 (80-162) minutes in the delayed group. Delayed patients were more likely to be female, older, to have lower acuity (CTAS 3) complaints, to live in dependent living situations, and to arrive on weekdays during day or evening hours. Delayed patients were less likely to require admission and, when admitted, more likely to go to the hospitalist service. All of these between group differences were significant at a $p<0.001$ level, suggesting that patients exposed to offload delays differ substantially based on identifiable characteristics from those offloaded promptly. Multivariable regression models (Table 3) show that the strongest predictors of EMS offload delay were arrival at one of the two slow offload sites, arriving on a weekday, and falling into the CTAS 3 triage category. Being female or having multiple previous ED visits was also associated with offload delay, whereas having a traumatic or musculoskeletal problem failed to show such an association.

Figure 1 and Table 4 show that 35,145 delayed patients were successfully matched to controls. In this study, propensity scores reflect the probability, based on all measured patient characteristics, that a particular patient will be triaged to an offload delay situation. Figure 2 shows excellent balance of propensity scores for the matched cohorts, suggesting that these groups were nearly identical in terms of prognostic factors, and were similar apart from exposure (or not) to offload delay. Table 4 confirms that, after propensity matching, covariate imbalance and between-group differences were essentially eliminated, although there were residual differences in the proportions of gastrointestinal and trauma-related complaints. Table 1 shows that, when comparing matched cohorts, the main outcomes were similar for controls and offload-delayed patients, although the latter experienced 2.4 hour prolongation of ED LOS and $0.4 \%$ lower 7 -day mortality rates. Table 5 demonstrates similar outcomes for the unmatched analysis.

\section{DISCUSSION}

This study compares 35,000 high-acuity EMS arrivals who received timely emergency access and 35,000 wellmatched patients who suffered substantial offload delays. Such delays are undesirable, cause patient discomfort and dissatisfaction, lead to suboptimal hallway care, prolong ED LOS, and take EMS crews out of service. However, we did not find that they were associated with increased patient mortality or prolonged hospital LOS.

Previous research shows that ED boarding, with delays to inpatient care, is associated with prolonged hospital LOS and increased mortality. ${ }^{12-15}$ We hypothesized that emergency offload delays would be similarly detrimental for high-acuity EMS patients; however, prior research in this area is limited. Our findings are similar to those of a multicentre Australian study, which reported that offload delays $>30$ minutes led to other process delays but did not increase patient mortality. ${ }^{10,} 16$ They are also concordant with a case-control study showing that offload delays were associated with delayed triage (10 v. 4 minutes) and prolonged ED LOS, but not with in-hospital mortality. ${ }^{16,} 17$ 


\begin{tabular}{|c|c|c|c|c|}
\hline & Control & Delay & Difference & $95 \% \mathrm{Cl}$ \\
\hline $\mathrm{n}(\%)$ & 35,145 & 35,145 & & \\
\hline Median offload delay: IOR & $8 \min (6,11)$ & $109 \min (79,162)$ & 101 & 100,102 \\
\hline Male sex & $16,519(47.0)$ & $16,413(46.7)$ & $0.3 \%$ & $-0.4,1.0$ \\
\hline Mean age $(S D)^{*}$ & $60.5(22.5)$ & $60.0(22.0)$ & 0.5 & $0,0.9$ \\
\hline CTAS 2 & $16,043(45.6)$ & $16,247(46.2)$ & $0.6 \%$ & $-0.2,1.3$ \\
\hline CTAS 3 & $19,102(54.4)$ & $18,898(53.8)$ & $0.6 \%$ & $-0.2,1.3$ \\
\hline Fast offload site & $22,870(65.1)$ & 23,515 (66.9) & $1.8 \%$ & $1.1,2.5$ \\
\hline Dependent living $\wedge$ & $5,750(16.4)$ & $5,593(15.9)$ & $0.5 \%$ & $-0.1,0.9$ \\
\hline \multicolumn{5}{|l|}{ Arrival time } \\
\hline Day & $12,193(34.7)$ & $12,036(34.2)$ & $0.5 \%$ & $-0.2,1.1$ \\
\hline Evening & $11,984(34.1)$ & 12,225 (34.8) & $0.7 \%$ & $-0.1,1.4$ \\
\hline Night & $10,968(31.2)$ & $10,884(31.0)$ & $0.2 \%$ & $-0.4,0.9$ \\
\hline Weekday arrival & $26,051(74.1)$ & $26,459(75.3)$ & $1.2 \%$ & $0.5,1.8$ \\
\hline ED visits prior year* & $1.17(1.23)$ & $1.18(1.23)$ & 0.01 & $-0.5,1.8$ \\
\hline \multicolumn{5}{|l|}{ Complaint category } \\
\hline Medical & $6,226(17.7)$ & $6,803(19.4)$ & $1.7 \%$ & $1.1,2.2$ \\
\hline Gastrointestinal & $5,548(15.8)$ & $8,253(23.5)$ & $7.7 \%$ & $7.1,8.3$ \\
\hline Cardiovascular & 6,077 (17.3) & $6,110(17.4)$ & $0.1 \%$ & $-0.5,0.7$ \\
\hline Neurologic-mental health & $7,277(20.7)$ & $7,382(21.0)$ & $0.3 \%$ & $-0.3,0.9$ \\
\hline Trauma-related & $8,408(23.9)$ & $5,029(14.3)$ & $9.6 \%$ & $9.0,10.2$ \\
\hline Other & $1,609(4.6)$ & $1,568(4.5)$ & $0.1 \%$ & $-0.2,0.4$ \\
\hline \multicolumn{5}{|l|}{ Admitting service } \\
\hline Hospitalist & $5,681(16.2)$ & $5,486(15.6)$ & $0.6 \%$ & $0,1.1$ \\
\hline Medicine & $3,222(9.2)$ & $3,325(9.5)$ & $0.3 \%$ & $0.1,1.0$ \\
\hline Surgery & $2,708(7.7)$ & $2,792(7.9)$ & $0.2 \%$ & $-0.2,0.6$ \\
\hline Cardiac & $783(2.2)$ & $756(2.2)$ & $0.0 \%$ & $-0.1,0.3$ \\
\hline ICU & $250(0.7)$ & $245(0.7)$ & $0.0 \%$ & $-0.1,0.1$ \\
\hline Psychiatry & $388(1.1)$ & $408(1.2)$ & $0.1 \%$ & $-0.1,0.2$ \\
\hline Other & $1,356(3.9)$ & $1,320(3.9)$ & $0.1 \%$ & $-0.2,0.4$ \\
\hline
\end{tabular}

The absence of any apparent harm signal in our data is counterintuitive, but there are several plausible explanations. The first is that triage nurses are good at their job and able to select a lower-risk patient population for hallway placement when ED stretchers are blocked. The second is that ongoing observation by hallway EMS crews and close communication with ED staff during the delay interval provides a second chance to identify at-risk patients who may have seemed stable during the initial triage interaction.

A critical operational factor, not typical of all EDs, which could mitigate delay-related morbidity, is the willingness of many Calgary physicians to see the next waiting patient regardless of their location (even in EMS hallways). Additional analysis of our data shows that 8,569 offload-delayed patients $(24.5 \%)$ were seen by a physician prior to reaching a care space, and that median (IQR) time from stretcher placement to physician assessment was 22 minutes (2-64) for delayed patients versus 36 minutes (11-83) for controls. Hallway physician assessments, along with a willingness of Calgary EMS crews to carry out many physician orders, including IV fluid infusions, analgesics, anti-emetics, and even transporting patients for diagnostic imaging, means that much care traditionally delayed until after ED stretcher placement now occurs before the patient reaches a care space. It is likely that these processes mitigated potential harms associated with offload delay and raise caution that our results may not be generalizable to all settings.

Despite failing to establish a link to mortality, our study highlights the magnitude of the problem, with $40 \%$ and $25 \%$ of high-acuity EMS patients experiencing offload delays of greater than 30 and 60 minutes, respectively.

Local data show that, despite diverse efforts to address them, offload delays are rising over the last 5 years. This 

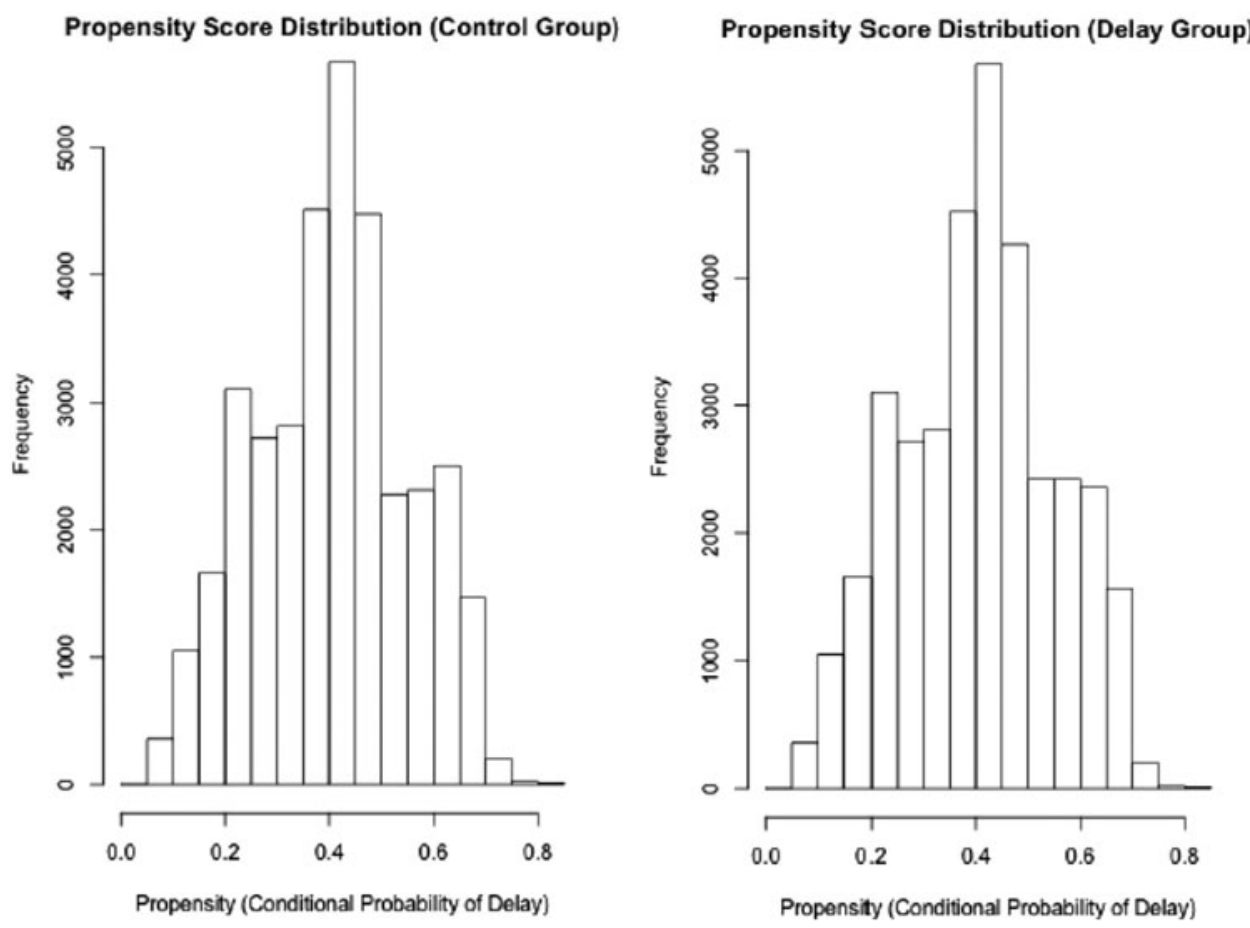

Figure 2. Propensity score distribution for matched (control and delayed) patients.

\begin{tabular}{|c|c|c|c|c|}
\hline & Control & Delay & Difference & $95 \% \mathrm{Cl}$ \\
\hline n (\%) & 70,652 & 41,016 & & \\
\hline Left against advice & $444(0.6)$ & $287(0.7)$ & $0.1 \%$ & $-0.03,0.2$ \\
\hline Left without being seen & $315(0.4)$ & $376(0.9)$ & $0.5 \%$ & $0.4,0.6$ \\
\hline ED LOS (all) in hours* & $8.4(7.4)$ & $10.8(9.1)$ & 2.2 & $2.4,2.6$ \\
\hline Hospital LOS (days)* & $4.5(12.1)$ & $4.4(12.6)$ & 0.1 & $-0.6,2.4$ \\
\hline Death within 7 days & $1,809(2.6)$ & $864(2.1)$ & $0.5 \%$ & $0.3,0.6$ \\
\hline Death within 30 days & 2,557 (3.6) & $1,442(3.4)$ & $0.2 \%$ & $0.0,0.4$ \\
\hline
\end{tabular}

represents an increasingly important problem that will require a systematic approach to be solved. Such efforts may include enhanced efforts by EDs to develop innovative offload strategies, a heightened sense of accountability on the part of hospitals and EDs for arriving acutely ill patients, and hospital-level flow and access improvements to ensure more timely patient care. Together, these strategies may allow EMS providers to once again achieve their mandate of delivering emergency care in the community, rather than waiting within hospital corridors. ${ }^{3}$

\section{Limitations}

The most important limitation of this study is that we assessed only left-without-being-seen rates, ED and hospital LOS, and 7- and 30-day mortality. These are important but crude outcomes. Future studies should address the effect of offload delays on patient experience and syndrome-specific quality measures (e.g., time to myocardial infarction reperfusion), as well as EMS cost and operational performance (e.g., response times to high-acuity calls). It is possible that the degree of offload delay we studied was not sufficient to increase mortality and LOS, and that focus on patients with more extreme delays might demonstrate the hypothesized relationship with adverse outcomes. It is likely that hallway physician assessment and related early care mitigated the negative effects of offload delays, which is a potential threat to external validity. It is also important to clarify that, while propensity matching is an excellent quasi-randomization 
technique, it only adjusts for measured parameters and cannot incorporate triage nurse "gut feelings" or other less tangible factors that lead to the selection of patients for offload delay. Lastly, despite propensity matching, there was one residual between-group difference, with a larger proportion of trauma-related complaints in the control group. It is unclear what effect this difference may have had on group outcomes.

\section{CONCLUSION}

In this setting, high-acuity EMS arrivals exposed to offload delays did not have prolonged hospital LOS or higher mortality than comparable patients who received timely access.

Competing interests: None declared.

\section{REFERENCES}

1. Carter AJ, Gould JB, Vanberkel P, et al. Offload zones to mitigate emergency medical services (EMS) offload delay in the emergency department: a process map and hazard analysis. C7EM 2015;17(06):670-8.

2. Cooney DR, Wojcik S, Seth N, et al. Evaluation of ambulance offload delay at a university hospital emergency department. Int 7 Emerg Med 2013;6(1):15.

3. Cooney DR, Millin MG, Carter A, et al. Ambulance Diversion and Emergency Department offload delay: resource document for the National Association of EMS Physicians position statement. Prebosp Emerg Care 2011;15(4):555-61.

4. Schwartz B. Transfer of care and offload delay: continued resistance or integrative thinking? CFEM 2015;17(6):67984, doi:10.1017/cem.2014.62.

5. Schwartz B, Cass D, Christian M, et al. Improving access to emergency services: a system commitment. The Report of the Hospital Emergency Department and Ambulance Effectiveness
Working Group. Ontario Ministry of Health and Long Term Care; 2005.

6. Schull MJ, Lazier K, Vermeulen M, et al. Emergency department contributors to ambulance diversion: a quantitative analysis. Ann Emerg Med 2003;41:467-76.

7. Affleck A, Parks P, Drummond A, et al. Emergency department overcrowding and access block. CFEM 2013;15 (6):359-70.

8. Alberta Innovates. ARECCI Ethics Screening Tool; 2010. Available at: http://aihealthsolutions.ca/arecci/screening/ (accessed October 23, 2016).

9. The Canadian Triage and Acuity Scale, Combined Adult and Paediatric Educational Program. Participant's Manual. CAEP and CTAS National Working Group; 2013:17-19.

10. Crilly J, Keijzers G, Tippett V, et al. Improved outcomes for emergency department patients whose ambulance off-stretcher time is not delayed. Emerg Med Australas 2015;27:216-24.

11. Ho DE, Imai K, King G, Stuart EA. MatchIt: Nonparametric preprocessing for parametric causal inference. 7 Stat Softw 2011;42(8):1-28.

12. Guttmann A, Schull MJ, Vermeulen MJ, Stukel TA. Association between waiting times and short term mortality and hospital admission after departure from emergency department: population based cohort study from Ontario, Canada. BM7 2011;342:d2983, doi:10.1136/bmj.d2983.

13. Richardson DB. Increase in patient mortality at 10 days associated with emergency department overcrowding. Med f Aust 2006;184(5):213-6.

14. Sprivulis PC, Da Silva JA, Jacobs IG, et al. Association between hospital overcrowding and mortality among patients admitted via Western Australian emergency departments. MFA 2006;184:208-12.

15. Singer AJ, Thode Jr HC, Viccellio P, Pines JM. The association between length of emergency department boarding and mortality. Acad Emerg Med 2011;18(12):1324-9.

16. Li M, Vanberkel P, Carter AJE. A review on ambulance offload delay literature. Health Care Manag Sci 2018; epub, doi:10.1007/s10729-018-9450-x.

17. Hitchcock M, Crilly J, Gillespie B, et al. The effects of ambulance ramping on emergency department length of stay and in-patient mortality. Australas Emerg Nurs 2010;13:17-24, doi: 10.1016/j.aenj.2010.02. 